\title{
A multistage stochastic programming asset-liability management model: an application to the Brazilian pension fund industry
}

\author{
Alan Delgado de Oliveira ${ }^{1} \cdot$ Tiago Pascoal Filomena ${ }^{1}$. \\ Marcelo Scherer Perlin' ${ }^{1}$ Miguel Lejeune ${ }^{2}$. \\ Guilherme Ribeiro de Macedo ${ }^{1}$
}

Received: 24 May 2015/Revised: 6 December 2015/Accepted: 26 February 2016/

Published online: 31 March 2016

(C) Springer Science+Business Media New York 2016

\begin{abstract}
This paper proposes a multistage stochastic programming approach for the asset-liability management of Brazilian pension funds. We generate asset price scenarios with stochastic differential equations-Geometric Brownian Motion model for stocks and Cox-Ingersoll-Ross model for fixed income securities. Intertemporal solvency regulatory rules for Brazilian pension funds are considered endogenously in the model and enforced with a combinatorial constraint. A VaR probabilistic constraint is incorporated to obtain a positive funding ratio at each time period with high probability. Our approach uses multiple trees to provide a representative characterization of the uncertainty and is not computationally prohibitive. We evaluate the insolvency probability under different initial funding ratios through extensive simulations. The study reveals that the likely decrease of interest rate premiums in the next years will force pension fund managers to significantly change their portfolio strategies. They will have to take more risk in order to deliver the cash flows required to cover the liabilities and satisfy the regulatory constraints.
\end{abstract}

Alan Delgado de Oliveira

alan.delgado@ufrgs.br

Tiago Pascoal Filomena tpfilomena@ea.ufrgs.br

Marcelo Scherer Perlin marcelo.perlin@ufrgs.br

Miguel Lejeune

mlejeune@gwu.edu

Guilherme Ribeiro de Macedo guilherme.macedo@ufrgs.br

1 Business School, Federal University of Rio Grande do Sul, Porto Alegre, Brazil

2 GWSB, The George Washington University, Washington, DC, USA 
Keywords ALM - Brazilian pension funds - Stochastic optimization - Scenario trees

\section{Introduction}

Asset-liability management (ALM) is a classical topic in financial optimization and is increasingly needed for fund managers operating in highly uncertain markets, such as those in developing countries. In simple terms, ALM's central problem is to develop an investment strategy that permits to cover the liabilities over a multiperiod horizon (Ziemba 2003). To enable this objective, the left-side (assets) and the right-side (liabilities) of the balance sheet must be matched (Adam 2007; Mitra and Schwaiger 2011). ALM models have been used in a variety of environments, ranging from pension funds (Josa-Fombellida and Rincón-Zapatero 2012; Gülpinar and Pachamanova 2013), insurance companies (Frangos et al. 2004; Consiglio et al. 2006; Asimit et al. 2014; Asanga et al. 2014), banks (Mukuddem-Petersen and Petersen 2008; Uryasev et al. 2010), corporate and public debt management (Date et al. 2011; Consiglio and Staino 2012; Valladão and Veiga 2014), to personal finance (Nielsen and Poulsen 2004; Rasmussen and Clausen 2007; Consiglio et al. 2007; Pedersen et al. 2013). Zenios and Ziemba (2006, 2007) provide a comprehensive overview of the theoretical and methodological developments in the ALM field and illustrate their application with a few case studies. This study focuses on the modeling of the specific rules and conditions to which the Brazilian pension fund industry is subjected.

Stochastic programming techniques and models have been applied to ALM since the seventies (Bradley and Crane 1972). Cariño et al. (1994) were probably the first to present a model with a commercial application. Subsequently, Boender (1997) proposed a large-scale model in which heuristics techniques are employed to determine the investment strategy. Ever since, multistage stochastic programming approaches have become a trend (see, e.g., Consigli and Dempster 1998; Kouwenberg 2001). Kouwenberg (2001) focused on the challenge of generating representative scenarios, which is a key aspect in multistage stochastic programming. Stochastic programming ALM models involving non-neutral risk measures and based on the CVaR measure (see, e.g., Rockafellar and Uryasev 2000; Bogentoft et al. 2001; Kilianová and Pflug 2009; Ferstl and Weissensteiner 2011) and on the inclusion of jumps for the asset prices (Josa-Fombellida and RincónZapatero 2012) have recently been proposed.

However, the legislative side of the ALM problem has seldom been the primary concern of the existing models, especially for emerging markets. Fund managers are bound to comply to laws in their judicial system and, therefore, the practice of ALM should also consider this particular set of restrictions. The objective of this study is to present the regulatory framework faced by the Brazilian pension funds' industry and to develop a multistage stochastic programming model that explicitly accounts for the set of ALM regulatory rules in Brazil. More specifically, we focus on the socalled defined benefit (DB) plan (Ziemba 2003), which is the most commonly used plan in Brazilian public institutions. In DB plans, the benefits received by the 
members of the plan (i.e., liabilities) are defined in advance which makes the fund liabilities almost deterministic and contrasts with the stochastic nature of assets' returns. Recent changes in the Brazilian capital markets is the main motivation for this application, as presented by Dupačová and Polívka (2009) and Kilianová and Pflug (2009) for other emerging markets. Brazilian pension fund managers have been used to almost exclusively invest in fixed income securities. However, with the capital markets and country developments, the long-term trend of the interest rate is decreasing. In this study, we investigate the possible changes in portfolio allocation due to this new economic environment and to the strict regulation.

Our study proposes a multistage stochastic programming ALM model with chance and combinatorial constraints which is motivated and can be applied by the Brazilian pension fund industry. The chance constraint enforces a Value-at-Risk $(\mathrm{VaR})$ requirement to keep the pension fund solvent across time with a high probability. The combinatorial constraint represents endogenously an intertemporal solvency regulation imposed by the Brazilian pension fund legislation. We construct multiple binary trees and each gives the same importance to catastrophic and normal economic scenarios. Thus, the model tends to be more conservative, an important feature for long-term survivorship in highly volatile environments, such as the Brazilian market.

The scenario generation relies on suggestions given by Kouwenberg (2001) and its key ingredients are the use of multiple trees and Stochastic Differential Equations (SDEs) to simulate the asset prices. The fixed income asset prices are simulated with the mean-reverting Cox-Ingersoll-Ross model (CIR), which guarantees the interest rate to be non-negative (Cox et al. 1985). Stock prices are generated with Geometric Brownian Motion (GBM). Some earlier studies pertaining to portfolio and ALM models have also used SDEs, but they focus on methods in which the portfolio allocation is kept fixed throughout the time (Merton 1973, 2001; Kim and Omberg 1996; Milevsky 1998; Wachter 2002). Notably different from the single tree approach typically used in the existing literature (see, e.g., Kouwenberg 2001), we implement an extensive scenario generation method to construct multiple trees. We solve the multistage stochastic programming problem corresponding to each tree and use a variant of the resampling method proposed by Michaud and Michaud (2008) to derive the final investment strategy.

Using empirical data for a specific Brazilian pension fund, we estimate its insolvency probability for different initial funding ratios. The results show that Brazilian pension fund managers shall modify their investment behavior and strategies in the near future: they will be pressured to increase their positions in riskier assets if the long-term downward trend of interest rates gets confirmed. As funds managers become less risk averse, their fund's insolvency probability will increase. However, if pension fund managers decide to keep their current risk profile (in terms of risk allocation and insolvency probability), pension fund's members external contributions would have to be raised in the next years.

The paper is organized as follows. In Sect. 2, we discuss the pension funds industry and the capital markets in Brazil. We motivate and formulate the stochastic programming model in Sect. 3. Section 4 describes the scenario generation techniques, while the algorithmic procedure and the data used in the numerical tests 
are outlined in Sect. 5. The results of the application of the model to the Brazilian market are presented in Sect. 6. Concluding remarks are provided in Sect. 7.

\section{Pension funds and capital markets in Brazil}

Pension funds play an important role in the Brazilian financial system by promoting financial stability for future retirees. In 2014, according to the Brazilian Association of Closed Supplementary Pension Funds (2014), the total nominal value of Brazilian pension funds assets was approximately 219 billions US dollars. The value was distributed across 317 different pension funds with varying sizes. Most of the pension funds are from private institutions.

In Brazil, every pension fund ${ }^{1}$ is under the supervision of the Board of the Pension Funds Management, which is a regulatory authority of the Brazilian National Financial System. The pension fund's auditing activities are managed by the Supplementary Pensions Department that acts as an watchdog for the existing standards. Both are subordinated to the National Monetary Council, the highest level authority in the Brazilian financial system. The private social entities in Brazil are organized in the form of non-profit foundations or civil societies and are accessible only to private employees of a company, group of companies or public employees (federal and state wide). Every investor of a pension fund is called a member.

The main legislation regarding pension's fund asset allocation limits and operation was designed by the National Monetary Council (Brazilian Central Bank 2012). In Brazil, a pension fund may invest the members' money in the following categories: fixed income, equity, structured investments, investment abroad, properties, and operations with participants. The maximum allocation for each instrument is $100,70,20,10,8$, and $15 \%$ respectively, and is aimed at controlling the pension's fund financial risk and protecting their members. There is no minimal allocation imposed for any of the instruments.

Solvency across time is another crucial consideration for Brazilian pension funds. According to the Ministry of Social Welfare (2008), the funding ratio, defined as the ratio of current assets to the present value of future liabilities, cannot be smaller than one in more than two consecutive years. The goal of this rule is to protect the members' wealth by ensuring a certain level of liquidity for the pension fund.

Currently, the fixed income allocation is highly predominant in the case of Brazilian pension funds. It can be explained by the high real interest rate that allows managers to reach, in most cases, the actuarial target without taking much risk. In April 2015, the domestic real short-term interest rate was approximately $6.5 \%$ per year, a very high risk premium that discourages managers to take positions in riskier assets.

However, the context in which Brazilian pension fund managers operate is changing. As in the rest of the world, life expectancy (and thereby liabilities of pension funds) in Brazil has increased, and the high real interest rate tends to

\footnotetext{
${ }^{1}$ Also called in Portuguese Entidade Fechada de Previdencia Complementar (EFPC).
} 
normalize at lower levels as the monetary policy instrument reaches the objective of holding the domestic inflation. One of the objectives of this paper is to investigate the consequences of the modified socio-economic context on the asset allocation strategies pursued by Brazilian pension funds.

The proposed multistage stochastic programming ALM model captures the economic changes and regulations in Brazil. The scenario generation method accounts for the modifications of the economic environment. The stochastic programming model incorporates constraints specific to the legislative regulations. The model enforces endogenously the intertemporal funding ratio constraint imposed by the current legislation. This makes the proposed model directly applicable by the Brazilian ALM practitioners. We present the specifics of the proposed model in the next section.

\section{Stochastic ALM model}

The ALM paradigm resides in the allocation of a certain amount of wealth in a number of financial assets $i=1, \ldots, N$ in order to cover the liabilities $l_{t}$ in each period $t=1, \ldots, T$. The model takes the form of a stochastic and intertemporal dynamic allocation problem due to the randomness of the asset prices and the timedependency nature of the investment and rebalancing decisions. The investment policy is defined with three sets of variables: $X_{i t s}$ is the number of shares of asset $i$ to hold in time period $t$ and scenario $s$, while $B_{i t s}$ and $V_{i t s}$ respectively denote the number of shares of $i$ bought and sold in time $t$ and scenario $s$. The stochastic variable $\xi_{i t}$ is the price of asset $i$ in time $t$ and can take a finite number $(s=1, \ldots, S)$ of realizations denoted $P_{i t s}$. Table 1 presents the model notations.

The model enforces risk and regulatory restrictions and takes the form of a multistage stochastic programming problem with chance constraints formulated as follows:

$$
\begin{gathered}
\max \sum_{s=1}^{S} \sum_{i=1}^{N} p_{T s} P_{i T s} X_{i T s} \\
\text { s.t. } Q=\sum_{i=1}^{N} P_{i 0} X_{i 0} \\
X_{i t s}=X_{i(t-1) s}+B_{i t s}-V_{i t s}, t \in 1, \ldots, T, i=1, \ldots, N, s=1, \ldots, S \\
\mathbb{P}\left(\sum_{i=1}^{N} \xi_{i t} X_{i t} \geq K\left(L_{t}-F_{t}\right)\right) \geq \alpha_{t}, t=1, \ldots, T \\
\sum_{i=1}^{N} P_{i t s} V_{i t s}-\sum_{i=1}^{N} P_{i t s} B_{i t s}+f_{t}=l_{t}, t=1, \ldots, T, s=1, \ldots, S
\end{gathered}
$$


Table 1 Notation summary

\begin{tabular}{|c|c|}
\hline \multicolumn{2}{|c|}{ Sets-indices } \\
\hline$t$ & Time index (stage) $t=0,1, \ldots, T$ \\
\hline$i$ & Index of asset classes $i=1, \ldots, N$ \\
\hline$s$ & Index of scenarios $s=1, \ldots, S$ \\
\hline \multicolumn{2}{|c|}{ Decision variables } \\
\hline$X_{i t s}$ & Number of shares of assets $i$ to hold in time $t$ and scenario $s$ \\
\hline$B_{i t s}$ & Number of shares of assets $i$ to buy in time $t$ and scenario $s$ \\
\hline$X_{i 0}$ & Number of shares of assets $i$ hold initially $(t=0)$ \\
\hline$V_{i t s}$ & Number of shares of assets $i$ to sell in time $t$ and scenario $s$ \\
\hline$C_{t s}$ & $\begin{array}{l}\text { Binary variable taking value } 1 \text { if there is underfunding in time } t \text { and } \\
\text { scenario } s \text { and taking value } 0 \text { otherwise }\end{array}$ \\
\hline \multicolumn{2}{|c|}{ Random variables } \\
\hline$\xi_{i t}$ & Random price of asset $i$ in time $t$ \\
\hline \multicolumn{2}{|c|}{ Deterministic parameters } \\
\hline$Q$ & Initial wealth \\
\hline$\alpha_{t}$ & Reliability level in time $t$ \\
\hline$K$ & Legally required funding ratio \\
\hline$L_{t}$ & Present value of future liability $t=t+1, \ldots, T$ \\
\hline$l_{t}$ & Liability to be paid in period $t$ \\
\hline$F_{t}$ & Present value of future external contributions, $t=t+1, \ldots, T$ \\
\hline$f_{t}$ & External contributions in each period $t$ \\
\hline$M$ & Maximum amount of underfunding allowed \\
\hline$\rho$ & Discounting factor \\
\hline$\pi$ & Maximum weight of an asset in the portfolio \\
\hline$p_{t s}$ & Probability of scenario $s$ at time $t$ \\
\hline$P_{i t s}$ & Price of asset $i$ at time $t$ and scenario $s$ \\
\hline$P_{i 0}$ & Known initial $(t=0)$ price of asset $i$ \\
\hline
\end{tabular}

$$
\begin{gathered}
X_{i t s} P_{i t s} \leq \pi \sum_{i=1}^{N} X_{i t s} P_{i t s}, t=1, \ldots, T, i=1, \ldots, N, s=1, \ldots, S \\
K\left(L_{t}-F_{t}\right)-\sum_{i=1}^{N} P_{i t s} X_{i t s} \leq M C_{t s}, t=1, \ldots, T, s=1, \ldots, S \\
\sum_{j=0}^{2} C_{(t+j) s} \leq 2, t=1, \ldots, T-2, s=1, \ldots, S \\
X_{i t s}, B_{i t s}, V_{i t s} \geq 0, i=1, \ldots, N, t=1, \ldots, T, s=1, \ldots, S
\end{gathered}
$$




$$
C_{t s} \in\{0,1\}, t=1, \ldots, T, s=1, \ldots, S \text {. }
$$

The model maximizes the expected terminal value of the fund (1). The objective function reflects the goals of the fund manager who aims at reaching the largest possible gains in the last period while respecting risk, regulatory and liability constraints. At time $t=0$, there is no uncertainty affecting the allocation of the initial wealth $Q$ to the asset classes and the price $P_{i 0}$ of each asset is known in (2). The number $B_{0}$ of shares bought is equal to the number $X_{0}$ of shares detained at the end of the initial period. The linear equalities (3) are the share balance constraints and specify that the number of shares $X_{i t s}$ of asset $i$ in time $t$ and scenario $s$ is equal to the number of shares $X_{i(t-1) s}$ detained at the previous period augmented by the number of purchased shares $B_{i t}$ minus those sold $V_{i t}$ at time $t$. Since the asset prices are known and deterministic, we have $X_{i 0 s}=X_{i 0}, \forall s$. The chance constraints (4) enforces the funding ratio requirements. The funding ratio represents the long-term relation between assets and liabilities. The actual funding ratio $\beta_{t s}$ of a fund in time $t$ and scenario $s$ is computed as:

$$
\beta_{t s}=\frac{F_{t}+\sum_{i=1}^{N} P_{i t s} X_{i t s}}{L_{t}}, \quad t \in 1, \ldots, T, s \in 1, \ldots, S,
$$

where $\sum_{i=1}^{N} P_{i t s} X_{i t s}$ is the current asset value of the pension fund in scenario s. $L_{t}$ and $F_{t}$ are, respectively, the present value of the future liabilities and contributions discounted by $\rho$ :

$$
L_{t}=\sum_{j=t}^{T} \frac{l_{j}}{(1+\rho)^{j-t}},
$$

The initial funding ratio is denoted by $\beta_{0}=\left(F_{0}+\sum_{i=1}^{N} P_{i 0} X_{i 0}\right) / L_{0}$. A value of $\beta$ smaller than 1 signals that the value of the assets might become insufficient to cover the future liabilities and that the fund might run into solvency issues in the near future. The Brazilian legislation on pension funds requires the use of a discounting factor $\rho$ equal to $5 \%$.

Each probabilistic constraint (4) enforces a safety level on the funding ratio and does not allow it to fall below a specified threshold $K$ with some large prescribed probability level $\alpha_{t}$. The two parameters $K$ and $\alpha_{t}$ define the risk-aversion of the asset-liability management policy. The risk-aversion level increases monotonically with the value taken by $K$ and $\alpha_{t}$. In general, $K$ is between 1 and 1.5 , while $\alpha_{t}$ is defined on $[0.9,1)$. The constraints (4) can be viewed as some sort of VaR constraints that ensure that the value of the fund is at least equal to $K L_{t}$ in each period $t$ with probability at least equal to $\alpha_{t}$. Their purpose is to maintain the longterm solvency level of the fund. As discussed in Sect. 2, the Brazilian legislation defines $K=1$. Haneveld et al. (2010) considers some more risk-averse values for $K$ (i.e., 1.05 and 1.30). Note that the probabilistic constraints (4) are individual ones. Alternatively, we could have used joint chance constraints at each period $t$. Such an approach would not allow for the funding ratio to fall below a specified threshold $K$ with probability level $\alpha_{t}$ at $t$ and at any of the earlier periods $t^{\prime}=1, \ldots, t-1$. This 
would enforce stricter requirements, may be appropriate in practice, and is much more difficult to solve.

The stochastic equalities (5) are the cash balance constraints and model the relationship between the fund's cash inflows and outflows. Inflows include the sales of assets, yields, and external contributions, while outflows are the payments of liabilities and the purchases of assets. External contributions are payments made by members or sponsors to the pension fund. The stochastic constraints (6) are motivated by the Brazilian legislation that defines an upper bound $\pi$ on the proportion of the fund value invested in a particular asset. Each constraint (7) indicates if there is underfunding in period $t$ and scenario $s$. If this is the case, the binary variable $C_{t s}$ is forced to take value one. The parameter $M$ is a large positive number and represents the maximum acceptable underfunding value. The Brazilian regulation stipulates that the funding ratio of the pension fund must not be below the value of 1 for more than two years in a row. This requirement is enforced by the combinatorial constraints (8). They make sure that there is no underfunding in three consecutive periods for every scenario. Constraints (9) and (10) define the nonnegativity and integrality restrictions.

An equivalent mixed-integer programming problem can be formulated for the above multi-stage stochastic programming problem:

$$
\begin{array}{cl} 
& \max (1) \\
\text { s.t.: } & (2)-(3) ;(5)-(10) \\
& \sum_{s=1}^{S} p_{t s} C_{t, s} \leq 1-\alpha_{t}, t=1, \ldots, T
\end{array}
$$

Noticing that $\sum_{s=1}^{S} p_{t s}=1$ for $\mathrm{t}=1, \ldots, \mathrm{T}$, the knapsack constraints (12) ensure that the sum of the probabilities of the scenarios with underfunding is below the complement of the enforced reliability level $\alpha_{t}$.

\section{Scenario generation}

As discussed by Cariño et al. (1994) and Dupačová and Polívka (2009), the benefits of the insights provided by the model depends heavily on the quality and relevance of the scenarios generated to represent the stochasticity of the assets' prices. Simulating prices properly is essential for the model's performance. In this study, the asset prices follow correlated SDEs of form:

$$
d \xi_{i t}=\mu\left(\xi_{i t}, t\right) d t+\sigma\left(\xi_{i t}, t\right) d W_{i t} .
$$

$W_{i t}$ is a Wiener process normally distributed with mean zero and variance $\Delta$ for $t<t+\Delta$. If more than one asset is used in the simulation, we should take into account the returns' correlated errors between the different assets (Dempster et al. 2003). The correlation coefficients $\rho_{i j}$ between two assets $i$ and $j$ at any time $t$ are defined by: 


$$
d W_{i} \cdot d W_{j}=\rho_{i j} d t, \quad \rho_{i i}=1, \quad \forall i, j .
$$

We consider two assets in the model: stock $\left(\xi_{1 t}\right)$ and fixed income $\left(\xi_{2 t}\right)$. We use the widely known Geometric Brownian Motion model for stock prices (Neftci 1996; Duffie 2001):

$$
d \xi_{1 t}=\mu \xi_{1 t} d t+\sigma \xi_{1 t} d W_{1 t} .
$$

The GBM offers a known closed form solution:

$$
\xi_{1 t}=\xi_{1(t-1)} e^{\left(\mu-\frac{1}{2} \sigma^{2}\right) d_{t}+\sigma \epsilon \sqrt{d_{t}}},
$$

with $\epsilon \sim N(0,1)$. For the price of the fixed income asset, we use the Cox-IngersollRoss term structure model (Cox et al. , 1985) to avoid the negative values that interest rate simulations can take with Vasicek (1977). The fixed income asset is represented by:

$$
d \xi_{2 t}=\alpha\left(\mu-\xi_{2 t}\right) d t+\sqrt{\xi_{2 t}} \sigma d W_{2 t},
$$

where $\xi_{2 t}$ is the interest rate and $\Lambda \equiv(\alpha, \mu, \sigma)$ are model parameters. The drift function $\mu\left(\xi_{2 t}, \Lambda\right)=\alpha\left(\mu-\xi_{2 t}\right)$ is linear and presents a mean reverting property, i.e interest rate $\xi_{2 t}$ moves in the direction of its mean $\mu$ at speed $\alpha$. The diffusion function $\sigma^{2}\left(\xi_{2 t}, \Lambda\right)=\xi_{2 t} \sigma^{2}$ is proportional to the interest rate $\xi_{2 t}$ and ensures the interest rate to be always positive. It is important to point out that the simulation model is related to the spot price of two assets only, one stock and one fixed income instrument. Since we only have long positions in the assets and we are not using prices from the other instruments in the yield term structure of the Cox-IngersollRoss model, we have not detected any arbitrage opportunities in our simulations. However, it should be noted that in other applications it might be necessary to ensure that the simulations don't allow for arbitrage opportunities, resulting in unrealistic prices of financial assets. Suggestions on how to handle this issue can be found in Høyland and Wallace (2001), Klaassen (2002) and Consiglio et al. (2016).

\section{Data structure and algorithm}

We construct multiple multistage binary event trees with $T$ time periods (stages) and $S$ scenarios. Every node in a tree has two successors, except for the leaf nodes at time $T$. Therefore, the total number of nodes in the tree is $2^{T+1}-1$. Each path from the root to a leaf node represents a scenario, and the nodes represent decision points. The same probability is attributed to each node at the same time (stage). The pension fund manager makes his/her decisions in time $t$ and scenario $s$ based on the currently available information and future expectations of asset prices. This process is completed in time $T$. Each node is equally likely, and therefore the same probability is given to normal and extreme scenarios, which makes the approach conservative. This is an important and valuable feature for countries like Brazil 
where the market volatility is quite high when compared to more developed markets.

In the stochastic programming ALM model, a scenario tree must be constructed to depict as accurately as possible the uncertainty structure. It is important to reduce the bias in the generation of scenarios and trees. If one single tree is constructed, this issue could be to some extent overcome by generating a very large tree. This could however lead to the formulation of an enormous stochastic programming problem that could be extremely difficult to solve even approximately. As another alternative to alleviate the issue of scenario bias in a single tree, Kouwenberg (2001) proposes a random sampling adjustment to control the aleatory nature of the problem. In this context of information uncertainty, we design in this paper a method that is based on the generation of scenarios for multiple trees and the solution of an optimization problem of smaller size for each tree, which permits to keep the computational complexity and the solution times under control. This technique has some similarities with the resampled efficient frontier method proposed by Michaud and Michaud $(2008)^{2}$ for the construction of portfolio of risky securities. For ALM purposes, Figueiredo (2011) has also recently adopted a multiple scenario tree approach analyzed with the sample-average approximation presented by Linderoth et al. (2006). We provide below the pseudo-code of our algorithmic procedure.

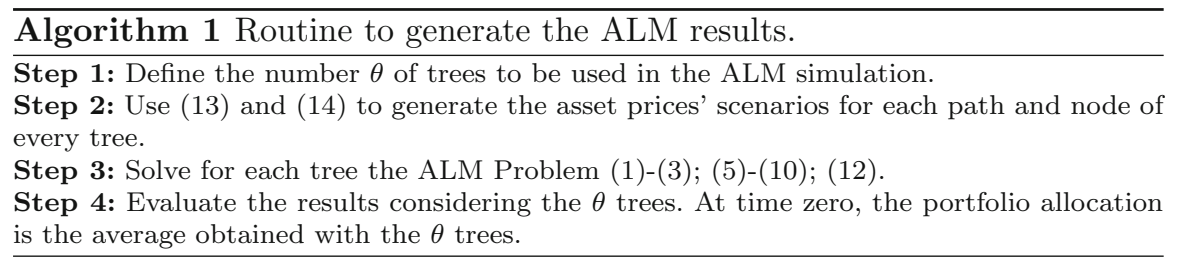

In Step 1, we define the number of trees to be solved for each parametrization (see, e.g.,Michaud and Michaud 2008). The value of $\theta$ must be sufficiently large so that the portfolio allocations are stable and small enough so that the approach does not become computationally prohibitive. Once the number $\theta$ of trees is defined, we generate in Step 2 scenarios for each tree using the method presented in Sect. 4. In Step 3, we solve to optimality the optimization problem (see Sect. 3) corresponding to each tree. In Step 4, we evaluate the results based on the optimal solutions of the $\theta$ trees. A key output of the model is the initial asset allocation, which is obtained by taking the average of the optimal initial asset allocations for each of the $\theta$ trees.

The resampling solution (Michaud and Michaud 2008) presents advantages and disadvantages. On the positive side, it limits extreme weight allocations that can arise with the classical mean-variance portfolio selection model. Additionally, the constructed portfolio is usually less sensitive to estimation error (Fletcher and Hillier 2001). However, Scherer (2002) raises some criticism to the resampling method. First, it is a heuristic without a theoretical economic rationale. Second, when long and short positions are allowed, the resampled efficient frontier is not

\footnotetext{
2 The resampling method was first published by Michaud (1998).
} 
necessarily an improvement over the classical efficient frontier (Markowitz 1952). Scherer (2002) also argues that resampling should be compared to Bayesian methods instead to the traditional mean variance. The literature is still controversial on the pros and cons of the results delivered by resampling (Markowitz and Usmen 2003; Ulf and Raimond 2006; Becker et al. 2015). There have been some recent attempts (see, e.g., Frahm 2015) to develop the theoretical foundations of the portfolio resampling approach. While the resampling method is certainly not exempt from criticism, our motivation to use it lies in the possibility it gives to consider many scenarios while preserving computational tractability.

The method described above is not without resemblance to the sample average approximation (SAA) method. As noted by Kim et al. (2014), the method can be applied when the sample and the true problems both enjoy features that are critical (e.g., continuity, differentiability) for optimization solvers. However, in terms of asymptotic efficiency, it was shown that the standard implementation of the SAA method does not perform as well as stochastic approximation. The performance gap is due to the fixed and very large size of the sample set, which makes extremely difficult to solve the resulting SAA formulation. To circumvent this issue, a method called retrospective approximation retrofit was recently proposed, in which the size of the sample set increases iteratively at a controlled rate. We refer the reader to Kim et al. (2014) for a comprehensive discussion of the principles, advantages, limitations, and implementation of the sample average approximation method.

\section{Application to the Brazilian market}

We implement the model presented in Sects. 3, 4 and 5 for a Brazilian pension fund. We use 10-period binary scenario trees with two asset classes. In order to calibrate the simulation of the fixed income asset, we collected data of the 1-month Brazilian LTN (similar to a T-Bill in the USA) as a proxy for the short-term interest rate. For the stocks, we collected the returns for the Brazilian Index IBOVESPA (similar to the S\&P 500 in the USA). We use maximum likelihood to estimate the parameters in equations (13) and (14). The training period is from January 2005 to January 2015. In Table 2, we present some descriptive return statistics for the two asset classes.

Table 2 highlights a peculiarity of the Brazilian capital market. Namely, the fixed income asset has an expected return $(9.6 \%)$ that is very close to the stocks expected return $(10.11 \%)$, but has a much lower volatility (i.e., $3.34 \%$ ) than stocks have (i.e., $28.6 \%$ ). It is thus easy to understand the preference of Brazilian pension fund managers for fixed income assets as their volatility is much lower than that of the

Table 2 Annualized return statistics for the two asset classes

\begin{tabular}{lcc}
\hline Asset & Mean (\%) & SD (\%) \\
\hline Stocks & 10.11 & 28.6 \\
Fixed income & 9.6 & 3.34 \\
\hline
\end{tabular}


stocks. However, as aforementioned, the fixed income premium is likely to decrease in Brazil, which could impact the pension funds asset allocations. The correlation between both assets is slightly negative and equal to -0.036 . Therefore, in a node of the tree, we can have the prices of both assets going up, both going down or up and down at the same time.

We design the scenario generation in $\mathrm{C}++$ and Matlab. AMPL and the CPLEX 12.5 solver are used to model and solve the optimization problems. We run CPLEX' standard branch-and-bound algorithm with its default settings on a 64-bit desktop with Intel Core i7-4510U $2 \mathrm{GHz}$ CPU with $8 \mathrm{~GB}$ of RAM. The computational performance is not the central goal of this paper, but it is worth pointing out the complexity of the model. For one single tree, we have 14,329 variables $(2,047$ integers), 2,047 nodes and 104,404 constraints. The computational time for the generation of the scenarios and the solution of the optimization problem varies from 7 to 21 seconds. Without the combinatorial regulatory constraint (8), the time decreases to around $2-3$ seconds.

\subsection{Number of trees - $\theta$}

We want to define the allocation that maximizes the wealth in the last period, while not violating any of the solvency, risk, and regulatory constraints. Our objective in this section is to determine the number of scenario trees needed to reach the stable state of the portfolio, i.e., stable allocations in fixed-income securities and stocks. Figure 1 shows how the average initial portfolio allocations vary with the number of trees.

The results displayed in Fig. 1 indicate that the initial portfolio allocations become fairly stable with 200 generated trees. The subsequent tests presented in this paper are obtained by using 300 trees in Algorithm 1. The computational time to run the method proposed in this paper with 300 trees takes from 35 to 105 minutes depending on the parametrization. The solution time varies predominantly and not monotonically with the value of the initial funding ratio. If this latter is large (above 1.25), the solution time is minimal and about equal to 35 minutes. The solution process is the longest when the initial funding ratio is slightly smaller than one.

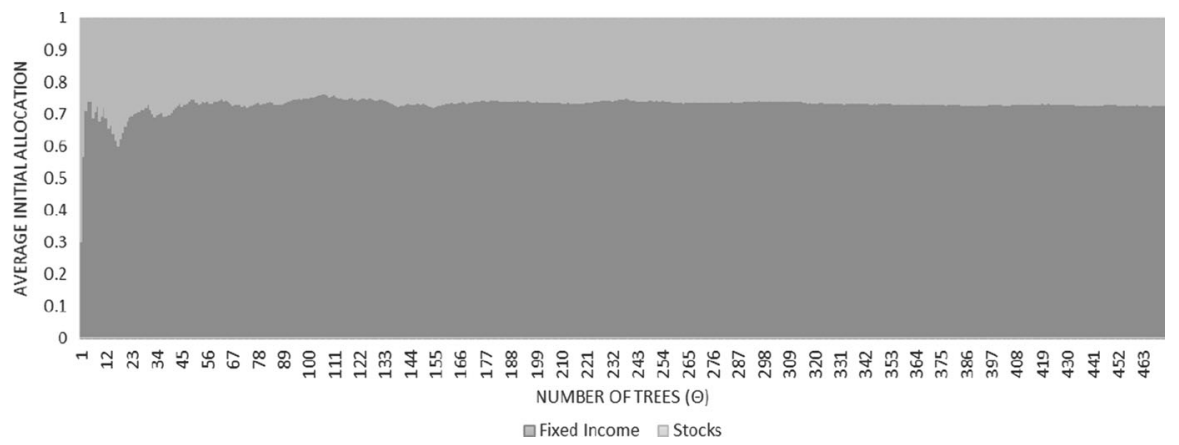

Fig. 1 Stability of average solution with respect to the number of trees - $\theta$ 


\subsection{Insolvency probability}

A key indicator of the financial health of the pension fund is its insolvency probability. A tree is said to be infeasible if there is no feasible solution for the corresponding optimization problem (see Step 3 in Algorithm 1). The probability of insolvency is defined as the following ratio:

$$
\mathbb{P}\left(\text { Insolvency } \mid \mathrm{VaR}_{90} \%\right)=\frac{\text { Number of infeasible trees }}{\text { Number of trees }}
$$

The model is constrained in such a way that the funding ratio must be above 1 with $90 \%$ probability in each period $t$ and includes a $90 \%$-VaR constraint at each period $t$. Furthermore, the intertemporal solvency regulation requires the funding ratio not be lower than $1(K=1)$ in more than two consecutive periods in any scenario. If in scenario $s$ the funding ratio is below 1 in stages $t$ and $t+1$, it must be above 1 in stage $t+2$ in scenario $s$. Another regulatory constraint is the $70 \%$ maximum amount of wealth to be allocated to stocks (see Sect. 2). The strong regulation and the high market volatility creates an environment in which the probability of a tree to be insolvent (infeasible) is not negligible.

Figure 2 displays how the insolvency probability varies in function of the pension fund's initial funding ratio $\beta_{0}$ for which we consider values ranging from 0.58 to 1.67. Note that the value of $K$, i.e., the legally required funding ratio, is kept equal 1 in each test and that we construct 300 trees for each considered value of the initial funding ratio. Each point in Fig. 2 corresponds to the mean portfolio allocation over 300 trees and the associated insolvency probability.

Figure 2 highlights that the insolvency probability is stable and low until the pension fund's initial funding ratio reaches 0.95 . The insolvency probability

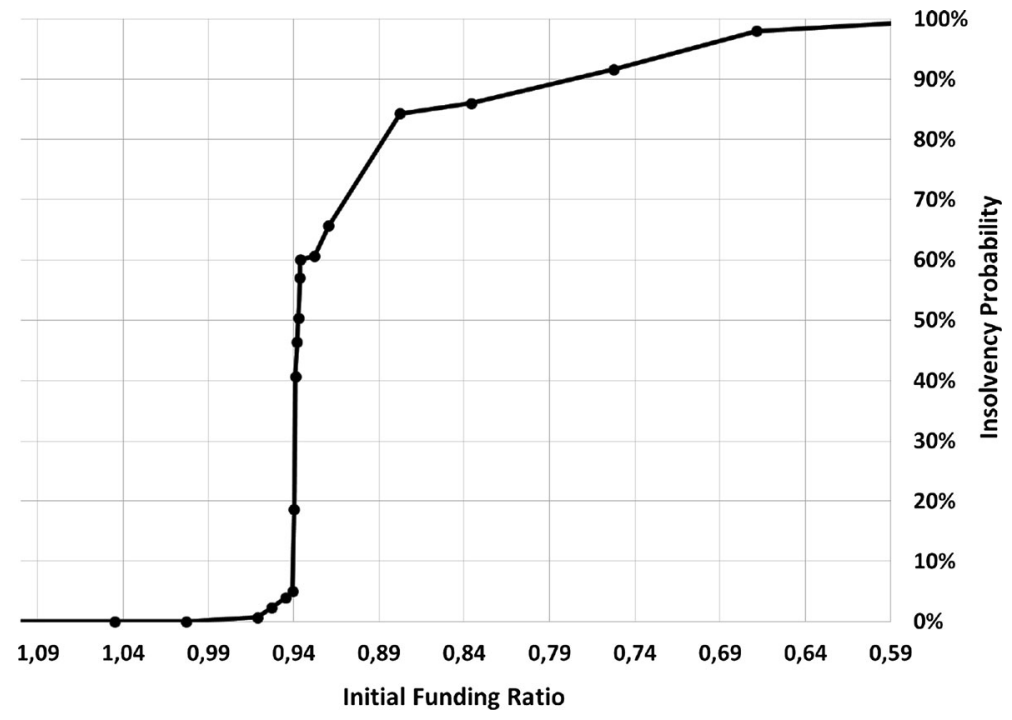

Fig. 2 Insolvency probability chart in terms of initial funding ratios 
increases very fast when the funding ratio goes below 0.95 and makes it virtually impossible to keep the fund solvent when the value of the funding ratio falls below 0.93 . For values of the funding ratios below 0.95 , the pension fund manager will definitely need additional external contributions. The external contributions can come from the members in two ways: (i) decrease in the future benefits (liabilities) or (ii) increase in the contributions without raising the benefits. Next, we present in Table 3 how the portfolio allocations and insolvency probability vary with the initial funding ratio.

As in the resampled efficiency frontier method (Michaud and Michaud 2008), the composition of the "final" fund is obtained by taking the average of the portfolio weights of all the 300 trees. Table 3 shows that the positions of the fund are not monotone with the initial value of the funding ratio. If the initial funding ratio is high (i.e., amount of assets is much higher than the present value of liabilities), the fund tends to allocate $70 \%$ and $30 \%$ in fixed income and stocks, respectively. The 70-30 \% fixed income-stock allocation coincides to the one used in many Brazilian pension funds (Brazilian Association of Closed Supplementary Pension Funds 2014). As the initial funding ratio becomes slightly lower than 1, the fund tends to concentrate more in fixed income to reduce its risks of not paying the liabilitiesthe fixed income allocation gets close to $80 \%$. Once the initial funding ratio gets smaller than 0.95 , the fixed income yield is not enough to cover the liabilities, a

Table 3 Portfolio allocation and insolvency probability under different initial funding ratios

\begin{tabular}{lllll}
\hline Fund ratio & Fixed-income bond $(\%)$ & Stocks $(\%)$ & N Insolv Scen & Insolv. Prob. (\%) \\
\hline 1.672 & 70 & 30 & 0 & 0.0 \\
1.463 & 67.3 & 32.7 & 0 & 0.0 \\
1.254 & 70.9 & 29.1 & 0 & 0.0 \\
1.045 & 72.6 & 27.4 & 2 & 0.7 \\
1.003 & 72.2 & 27.8 & 7 & 2.3 \\
0.961 & 81 & 19 & 12 & 4 \\
0.953 & 83 & 17 & 15 & 5 \\
0.945 & 82.1 & 17.9 & 56 & 18.7 \\
0.941 & 82.1 & 17.9 & 122 & 40.7 \\
0.940 & 73.1 & 26.9 & 139 & 46.3 \\
0.939 & 71.6 & 28.4 & 151 & 50.3 \\
0.938 & 70.4 & 29.6 & 171 & 57 \\
0.937 & 63 & 37 & 180 & 60 \\
0.936 & 64.4 & 35.6 & 182 & 60.7 \\
0.928 & 30 & 70 & 253 & 84.3 \\
0.919 & 30 & 70 & 258 & 86.0 \\
0.752 & 30 & 70 & 298 & 99.3 \\
0.669 & NA & NA & 300 & 100 \\
0.585 & NA & NA & 300 & 100 \\
\hline
\end{tabular}


larger part of the portfolio is then dedicated to stocks. The $70 \%$ stock allocation is the maximum amount allowed by the Brazilian legislation and such an allocation is associated with a very high insolvency probability. This V-shaped portfolio policy is somewhat similar to the results reported by Berkelaar and Kouwenberg (2003) and Siegmann and Lucas (2005). With lower initial funding ratios (lower wealth levels) the allocation tends to be concentrated in the risky asset.

We also tested additional assumptions for the pension fund. We assumed that the fund manager (or the regulator) becomes more risk averse. In such a case, we set $K=1.1$ (instead of 1) in (4). As expected, the insolvency curve plotted in Fig. 2 for $K=1$ shifts to the left for $K=1$. If we remove the intertemporal funding ratio regulatory constraint (8), the insolvency probability just slightly decreases.

\subsection{Allocation with a decreasing interest rate}

Despite the current sharp interest rate increase in 2014 and 2015 (more than 400 bps), a decreasing interest rate "looks like" a future tendency in Brazil. Dupačová and Polívka (2009) observed a similar trend in the Czech Republic. We shall now analyze the impact of a long-term decrease in the interest rate on the investment policy of Brazilian pension funds. In our analysis, we consider two scenarios that differ in the value of the initial funding ratio. In Fig. 3 panel (a) (resp., panel (b)), we consider a pension fund with initial funding ratio of 1.25 (resp., 0.94). We chose an initial funding ratio of 1.25 that corresponds to a financially healthy pension fund, while 0.94 is the critical level of the initial funding ratio (see Fig. 2) when the involvency probability of the pension fund changes significantly. The resulting portfolio is also constructed by taking the average asset positions over the optimal positions of the 300 trees.

Based on Fig. 3 panel (a), we observe that when the initial current asset value is much larger than the present value of future liabilities, the portfolio allocations are stable, i.e., around 70 and $30 \%$ allocated to fixed income and stocks, respectively. Despite the lower level of the interest rates, the funds do not increase their position in the risky assets due to their high volatility. Under this context, it is not needed to take more risks to be able to pay the liabilities. However, this conservative policy significantly decreases the future wealth of fund members. Now considering in Fig. 3 panel (b) funds with low initial funding ratios, we can see that, as the interest rate decreases, the position in stocks becomes larger in order to possibly generate larger returns allowing for the payments of the liabilities. When the interest rate is close to $5 \%$, the pension fund is required to take a riskier approach, investing more resources in stocks than in fixed income. This is a marked departure with the standard current allocations of pension funds and gives a clear indication the type of allocations most of Brazilian pension fund managers will have to adopt in the near future in case of lower interest rates.

In both cases displayed in Fig. 3, pension fund managers will have to change their portfolio allocation if the decrease of interest rate becomes a reality. On one hand, if the fund is financially healthy (initial funding ratio 1.25), this change is necessary to avoid the progressive erosion of the initial wealth and capital. On the other hand, if the resources of the fund are tight (i.e., initial funding ratio 0.94), this 


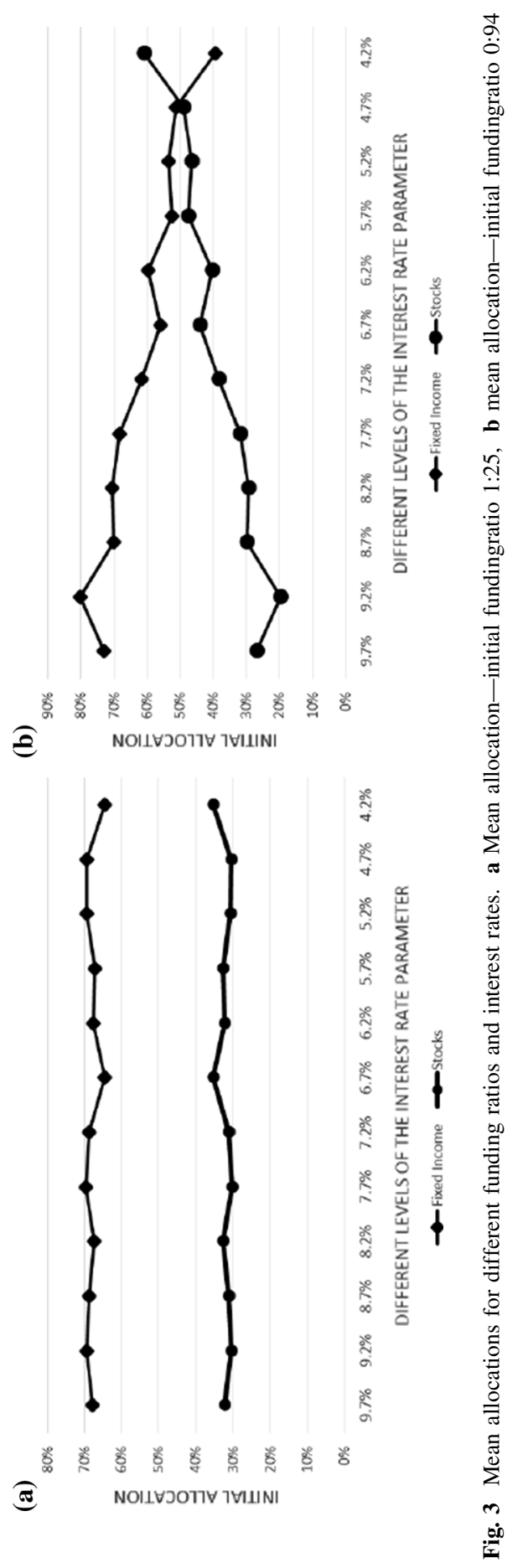


adjustment is fundamental to maintain the ability to cover the liability payments. Besides the modification of the investment strategy, it is likely that members will be asked to increase their contributions and/or to accept benefits of lesser value in the future.

\subsection{Robustness and scalability}

In this section, we focus on the out-of sample robustness and on the scalability with respect to the number of assets. First, we train the model on two different periods: Training A - from January 2005 to December 2013 and Training B-from January 2005 to December 2014. The application of the model built on the Training A (resp., Training B) data on the out-of-sample 2014 (resp. 2015) data permit to evaluate the out-of-sample performance of the model. As the return data are not at the present time available for the entire 2015 year, the 2015 out-of-sample analysis is based on the January 2015 - November 2015 period. To obtain the initial portfolio allocation, we use the method presented in Sect. 5. We test the model with three different initial funding ratios: $0.95,1.00$ and 1.05 . These initial funding ratios become the benchmark for the out-of-sample tests presented in Table 4.

We have chosen funding ratios that are close to the critical value of 1 . We have also avoided ratios below 0.95 because of the $\mathrm{V}$-shaped behavior towards the riskier asset documented in the literature (Berkelaar and Kouwenberg 2003; Siegmann and Lucas 2005) and discussed in Sect. 6.2. A $15 \%$ federal income tax discount was used for the out-of-sample portfolio return. Based on Table 4 and considering the initial level of 1, the out-of-sample funding ratio increases to reach 1.006 in 2014 and 1.025 in 2015. Similar results were obtained with the initial funding ratios of 0.95 and 1.05. The initial funding ratio pension fund' maintenance (or increase) in the out-of-sample tests shows the robustness of the model.

We also note that this study has been conducted by accounting for the main asset classes (i.e., stocks and fixed income) in the ALM context. Those are definitely the main investment options considered by pension fund managers in Brazil (Brazilian Association of Closed Supplementary Pension Funds 2014). Next, in order to analyze the scalability of the model, we consider a larger number of assets. We design an experiment for two and eight assets with the following features: 500 runs (generating the scenarios and optimizing the tree), each tree with ten periods and funding ratio of 1 . The objective here is to verify if the number of assets can be increased without making the computational performance prohibitive. The results showed that each run took on average 17.28 seconds for 2 assets and 22.30 seconds for 8 assets. The standard deviation was 1.59 and 4.2 seconds, respectively, for 2

Table 4 Out-of-sample tests with different funding ratios

\begin{tabular}{lllll}
\hline & \multicolumn{4}{l}{ Funding ratio (FR) } \\
\hline Initial FR & & 0.950 & 1.000 & 1.050 \\
Out-of-sample FR & 2014 & 0.958 & 1.006 & 1.066 \\
& 2015 & 0.982 & 1.025 & 1.085 \\
\hline
\end{tabular}


and 8 assets. Thus, the implementation can easily be scaled up to a larger number of assets.

\section{Conclusions}

The objective of this study is to develop and apply a multistage stochastic programming ALM model for a Brazilian DB pension fund that takes into account the dynamic of the domestic financial market and its regulatory idiosyncrasies. Besides the multistage aspect, the complexity of the model is exacerbated by (i) the enforcement of a VaR metric modelled with probabilistic chance constraints, and (ii) the intertemporal solvency regulation modelled with combinatorial constraints. Different economic scenarios are simulated with the GBM and CIR models and used to construct multiple multistage scenario trees. The proposed multiple scenario tree approach is inspired from the resampling efficiency frontier method and is aimed at enabling the consideration of a representative set and vast number of contingencies without making the algorithmic procedure computationally prohibitive.

The empirical analysis shows the link between the initial funding ratio on one hand and the insolvency probability and the positions of the fund on the other hand. A simulation assuming a decrease in the interest rate provides key insights about the likely changes in the investment strategies of the Brazilian pension funds.

A promising future research avenue is to switch the focus from defined benefit (DB) to defined contribution (DC) with minimum guarantees pension funds. For instance, the Brazilian public sector is currently experiencing this shift from DB to DC with some guarantees. Consiglio et al. (2015) not only discuss other countries in which this change is taking place but also present a model integrating option pricing and portfolio optimization to obtain asset allocations considering minimum guarantees.

Acknowledgments The authors thank the three anonymous referees and the two associate editors for their valuable comments and suggestions that greatly improved the quality of the paper. This work was funded by the following Brazilian Research Agencies: CAPES and FAPERGS.

\section{References}

Adam A (2007) Handbook of asset and liability management: from models to optimal return strategies, 1 st edn. Wiley, London

Asanga S, Asimit A, Badescu A, Haberman S (2014) Portfolio optimization under solvency constraints: a dynamical approach. North Am Actuar J 18(3):394-416

Asimit A, Badescu A, Siu TK, Zinchenko Y (2014) Capital requirements and optimal investment with solvency probability constraints. IMA J Manag Math, pp 1-31

Becker F, Gurtler M, Hibbeln M (2015) Markowitz versus Michaud: portfolio optimization strategies reconsidered. Eur J Financ 21(4):269-291

Berkelaar A, Kouwenberg R (2003) Retirement saving with contribution payments and labor income as a benchmark for investments. J Econ Dyn Control 27:1069-1097

Boender GCE (1997) A hybrid simulation/optimisation scenario model for asset/liability management. Eur J Oper Res 99(1):126-135 
Bogentoft E, Romeijn HE, Uryasev S (2001) Asset/liability management for pension funds using cvar constraints. J Risk Financ 3:57-71

Bradley SP, Crane DB (1972) A dynamic model for bond portfolio management. Manag Sci 19:139-151

Brazilian Association of Closed Supplementary Pension Funds (2014) Consolidade estatístico. http:// www.abrapp.org.br/Consolidados/Consolidado\%20Estat\%C3\%ADstico_12_2014.pdf. Accessed 05 Jan 2015

Brazilian Central Bank (2012) Resolution number 3792. http://www.bcb.gov.br/pre/normativos/res/2009/ pdf/res_3792_v1_O.pdf. Accessed 05 Jan 2015

Cariño DR, Kent T, Meyers DH, Stacy C, Sylvanus M, Turner AL, Watanabe K, Ziemba WT (1994) The Russel-Yasuda Kasai model: an asset/liability model for japanese insurance company using multistage stochastic programming. Interfaces 24(1):29-49

Consigli G, Dempster MAH (1998) Dynamic stochastic programming for asset-liability management. Ann Oper Res 81:131-161

Consiglio A, Staino A (2012) A stochastic programming model for the optimal issuance of government bonds. Ann Oper Res 193(1):159-172

Consiglio A, Saunders D, Zenios SA (2006) Asset and liability management for insurance products with minimum guarantees: the UK case. J Bank Financ 30(2):645-667

Consiglio A, Cocco F, Zenios SA (2007) Scenario optimization asset and liability modelling for individual investors. Ann Oper Res 152(1):167-191

Consiglio A, Tummiello M, Zenios S (2015) Designing guarantee options in defined contribution pension plans. Insur Math Econ 26:267-279

Consiglio A, Carollo A, Zenios SA (2016) A parsimonious model for generating arbitrage-free scenario trees. Quant Financ 16(2):201-212

Cox JC, Ingersoll JE, Ross SA (1985) A theory of the term structure of interest rates. Econometrica 53(2):385-408

Date P, Canepa A, Abdel-Jawad M (2011) A mixed integer linear programming model for optimal sovereign debt issuance. Eur J Oper Res 214(3):749-758

Dempster MAH, Germano M, Medova EA (2003) Global asset liability management. Br Actuar J 9:137-216

Duffie D (2001) Dynamic asset pricing theory. Princeton University Press, Princeton

Dupačová J, Polívka J (2009) Asset-liability management for Czech pension funds using stochastic programming. Ann Oper Res 165:5-28

Ferstl R, Weissensteiner A (2011) Asset-liability management under time-varying investment opportunities. J Bank Financ 35(1):47-62

Figueiredo D (2011) Investiment decision making for defined benefit Pension Funds: an multistage stochastic linear programing approach (in Portuguese). Master's thesis, School of Engineering - São Paulo State University, Brazil

Fletcher J, Hillier J (2001) An examination of resampled portfolio efficiency. Financ Anal J 57(5):66-74

Frahm G (2015) A theoretical foundation of portfolio resampling. Theory Decis 79(1):107-132

Frangos C, Zenios S, Yavin Y (2004) Computation of feasible portfolio control strategies for an insurance company using a discrete time asset/liability model. Math Comput Model 40(3G4):423-446

Gülpinar N, Pachamanova D (2013) A robust optimization approach to asset-liability management under time-varying investment opportunities. J Bank Financ 37(6):2031-2041

Haneveld WKK, Streutker MH, Van der Vlerk MH (2010) An ALM model for pension funds using integrated chance constraints. Ann Oper Res 177(1):47-62

Høyland K, Wallace SW (2001) Generating scenario trees for multistage decision problems. Manag Sci 47(2):295-307

Josa-Fombellida R, Rincón-Zapatero JP (2012) Stochastic pension funding when the benefit and the risky asset follow jump diffusion processes. Eur J Oper Res 220(2):404-413

Kilianová S, Pflug GC (2009) Optimal pension fund management under multi-period risk minimization. Ann Oper Res 166(1):261-270

Kim S, Pasupathy R, Henderson S (2014) A guide to sample average approximation. In: Fu M (ed) Handbook of simulation optimization, International series in operations research and management science. Springer, Berlin

Kim TS, Omberg E (1996) Dynamic nonmyopic portfolio behavior. Rev Financ Stud 9:141-161

Klaassen P (2002) Comment on generating scenario trees for multistage decision problems. Manag Sci 48(11):1512-1516 
Kouwenberg R (2001) Scenario generation and stochastic programming models for asset liability management. Eur J Oper Res 134(1):279-292

Linderoth J, Shapiro A, Wright S (2006) The empirical behavior of sampling methods for stochastic programming. Ann Oper Res 142(1):215-241

Markowitz H (1952) Portfolio selection. J Financ 7:77-91

Markowitz H, Usmen N (2003) Resampled frontiers versus diffuse bayes: an experiment. J Invest Manag 1(4):9-25

Merton RC (1973) Optimum consumption and portfolio rules in a continuous-time model. J Econ Theory $3: 373-413$

Merton RC (2001) Continuous-time finance. Blackwell Publishers Ltda, Cambridge

Michaud R (1998) Efficient asset management: a practical guide to stock portfolio optimization and asset allocation, 1st edn. Harvard Business School Press, Boston

Michaud R, Michaud R (2008) Efficient asset management: a practical guide to stock portfolio optimization and asset allocation, 2nd edn. Oxford University Press, Oxford

Milevsky MA (1998) Optimal asset allocation towards the end of the life cycle: to annuitize or not to annuitize? J Risk Insur 65(3):401-426

Ministry of Social Welfare (2008) Cgpc resolution number 26. http://www.previdencia.gov.br/arquivos/ office/3_081029-134807-632.pdf. Accessed 05 Jan 2015

Mitra G, Schwaiger K (eds) (2011) Asset and liability management handbook, 1st edn. Palgrave Macmillan, Basingstoke

Mukuddem-Petersen J, Petersen MA (2008) Optimizing asset and capital adequacy management in banking. J Optim Theory Appl 137(1):205-230

Neftci SN (1996) An introduction to the mathematics of financial derivatives, 1st edn. Academic Press, Cambridge

Nielsen SS, Poulsen R (2004) A two-factor, stochastic programming model of danish mortgage backed securities. J Econ Dyn Control 28:1267-1289

Pedersen AMB, Weissensteiner A, Poulsen R (2013) Financial planning for young households. Ann Oper Res 205(1):55-76

Rasmussen KM, Clausen J (2007) Mortgage loan portfolio optimization using multi-stage stochastic programming. J Econ Dyn Control 31:742-766

Rockafellar RT, Uryasev S (2000) Optimization of conditional value-at-risk. J Risk 2:21-41

Scherer B (2002) Portfolio resampling: review and critique. Financ Anal J 58(6):98-109

Siegmann A, Lucas A (2005) Discrete-time financial planning models under loss-averse preferences. Oper Res 53(3):403-414

Ulf H, Raimond M (2006) Portfolio choice and estimation risk. A comparison of bayesian to heuristic approaches. Astin Bull 36(1):135-160

Uryasev S, Theiler UA, Serraino G (2010) Risk-return optimization with different risk-aggregation strategies. J Risk Financ 11(2):129-146

Valladão DM, Veiga A (2014) A multistage linear stochastic programming model for optimal corporate debt management. Eur J Oper Res 237(1):303-311

Vasicek O (1977) An equilibrium characterization of the term structure. J Financ Econ 5:177-188

Wachter J (2002) Portfolio and consumption decisions under mean-reverting returns: an exact solution. J Financ Quant Anal 37:63-91

Zenios SA, Ziemba WT (2006) Handbook of asset and liability management-vol 1: Theory and Methodology, 1st edn. Elsevier, UK

Zenios SA, Ziemba WT (2007) Handbook of asset and liability management-vol 2: applications and case studies, 1st edn. Elsevier, UK

Ziemba WT (2003) The stochastic programming approach to asset. Liability and wealth management. AIMR Publisher, Vancouver, Canada and Londres, England 